\section{Библиография}

1. Закон за здравето, ДВ. бр.70 от 10.08.2004 г., последно изм. и доп 2018 г.

2. Закон за лечебните заведения, ДВ. бр.62 от 9.07.1999 г., последно изм. и доп. 2018 г.

3. Закон за съсловната организация на медицинските сестри, акушерките и асоциираните специалисти цел на професионалното развитие на медицинските сестри, ДВ. бр.46 от 3.06.2005 г., последно изм. и доп. 2016 г.

4. Наредба за ЕДИ за придобиване на висше образование за специалностите „Медицинска сестра” и „Акушерка” за ОКС „бакалавър”, изм. ДВ. Бр.88 от 9.11.2010.

5. Наредба за ЕДИ за придобиване на висше образование по специалността "Управление на здравните грижи" за образователно-квалификационните степени “магистър” и “бакалавър" от професионално направление "Обществено здраве” ДВ. бр.95 от 29.11.2005 г., последно изм. и доп. 2016

6. Наредба № 1 от 08.02.2011 г. за професионалните дейности, които медицинските сестри, акушерките, асоциираните медицински специалисти и здравните асистенти могат да извършват по назначение или самостоятелно ДВ. бр. 15 от 18.02.2011 г.
7. Наредба № 19 от 22 юли 1999 г. за водене на регистьр на лечебните заведения за извънболнична помощ и хосписите ДВ. бр.68 от 30.07.1999 г., последно изм. 2009 г.

8. Наредба № 1 от 22.01.2015 г. за следдипломно обучение в системата на здравеопазването, ДВ, бр. 7 от 27.01.2015 г.,

9. Национална здравна стратегия (2014-2020) (НЗС), приета с Решение на Народното събрание от 17.12.2015 г

10. Национална програма за развитие на България 2020, приета с Решение № 1057 на Министерския съвет от 20.12.2012 г.

11. Програма на правителството за стабилно развитие на Република България за периода 2014-2018 г., приета с Решение № 42 на Министерския съвет от 26.01.2015 г.

12. Национална стратегия за дългосрочна грижа, приета с Решение № 2 на Министерския съвет от 07.01.2014 г.

13. “Цели за здраве 2020“ - Концепция http://www.mh.government.bg/media/filer_public/2015/04/08/kontseptsiya-tseli-za-zdrave-2020.pdf

\section{Автор}

Профр. д-р Соня Тончева, Медицински университет - Варна

\title{
ПРОБЛЕМИ НА БЪЛГАРСКАТА ЗДРАВНА СИСТЕМА СПОРЕД ЖАЛБИТЕ И СИГНАЛИТЕ НА ПАЦИЕНТИТЕ КЪМ КЗД, ИАМО И СЪДА
}

\author{
Н. Джафер
}

\author{
PROBLEMS OF THE BULGARIAN HEALTH SYSTEM ACCORDING \\ TO COMPLAINTS AND SIGNALS OF THE PATIENTS TO CPD, EAMO \\ AND THE COURT \\ N. Dzhafer
}

Рез юме. Всяка здравна система има една основна задача - да решава здравните проблеми на хората. Потребителите на здравни грижи могат да изпратят своите жалби и сигнали за нередности към различни органи и институции. Работата включва преглед на подадените жалби и сигнали, свързани със здравеопазването към Комисията за защита от дискриминация (КЗД) (380 броя), Изпълнителната агенция „Медицински одит” (ИАМО) (3472 броя) и съдебната система (238 дела). Разгледани са периодите на съществуване на КЗД И ИАМО и десетгодишен период при съдилищата. Използвана е достьпната информация за дейността на тези институции, както и поискана специална за целта на тази публикация информация. Броят на жалбите, отправяни към дадена институциия най-вероятно се влияе от доверието към нея, начина на подаване и проиедурата по сезиране, уведомяването за проверката и резултата от нея.

S u m m a ry. Each healthcare system has one main task - to solve the health problems of people. Healthcare users can send their complaints and signals of irregularities to different bodies and institutions. The work includes a review of healthcare complaints and alerts submitted to the Commission for Protection from Discrimination (380), the Executive Agency,,Medical Audit" (3472) and the Judiciary (238 cases), examining the periods of existence of CPD and EAMO and a ten-year period in the courts. Useful information on the activities of these institutions, as well as information specifically requested for this publication, has been used. The number of complaints addressed to an institution is most likely influenced by its credibility, the way of filing and the referral, the notification of the investigation and its outcome.

Key words: Patient Complaints, Commission for Protection against Discrimination (CPD), Medical Audit Executive Agency (EAMO), Court

\section{Въведение}

Основно право на пациента според Хартата за права̀та на пациентите е правото му на подаване на жалби, ако не са спазени права̀та му като такъв. Класическата деонтология е в основата на медицинското право, което по презумпция трябва да се базира на стандартизиране, правила, алгоритми, които могат да се обективизират и оценят. От тук произтича важността на т. нар. правила за добра медицинска практика, медицински стандарти, клинични пътеки като метод за поведение и разплащане и най-вече като начини за стандартизация и оценка за спазване. Отговорността в здравеопазването е административноправна и наказателноправна. Тя може да е гражданска или съсловна, както и морално-етична $[5,7,8]$. Освен към институции със специално вменени за- дължения и създадените специфични за целта структури за контрол и надзор в здравеопазването (ИАМО) [3], граждани и организации могат да сигнализират други органи за проблеми в здравната система. Омбудсманът на Р. България [2] и Комисията за защита от дискриминация (КЗД) $[1,4]$ ако бъдат сезирани или се самосезират, са институции и органи с по-широки правомощия, които включват и правомощия, и ангажименти, свързани със здравеопазването.

\section{Цем и заАачи}

Целта и свързаните с нея задачи са да се анализират броят на подадените жалби, тенденцията за промяна в броя им, видовете проблеми, които засягат. Необходимо е да се направи следното уточнение: Освен, че са регламентирани 
по различен законов ред като обхват, дейност, компетенции и възможност за проверка и санкции при получени жалби и сигнали, различните проучени институции публикуват и/или не публикуват информация и данни за проверките и резултатите. Предоставяната информация не е унифицирана и достатьчна, дори когато е поискана специално, което я прави трудна за обобщение и анализ. Въпреки това, тази публикаџия е опит да се сравнят данните за сигналите, свързани със здравната система и тенденциите и проблемите в нея.

\section{Материац и методи}

Работата включва преглед на подадените жалби и сигнали, свързани със здравеопазването към Комисията за зацичта от дискриминация (380 броя), Изпълнителната агенция за медицински одит (ИАМО) (3472 броя) и съдебната система (238 дела). Използвана е достьпната информация за дейността на тези институции, както и поискана специална информация за целта на тази публикация. Разгледани са годишните отчети за периодите на съществуване на съответните институичи от възникването им - КЗД (2005-2017) И ИАМО (2012-2017), както и десетгодишен период при съдилищата (2007-2017).

\section{Резултати}

\section{Жалби и сигнали към Комисията за защита от дискриминация}

Броят на постъпилите оплаквания до КЗД, свързани с твърдения за засегнати права̀ на граждани по отношение на функционирането на системата за здравеопазване е $\mathbf{3 8 0}$, като след преценка за редовност и допустимост са образувани производства за защита от дискриминация, по които са постановени 360 решения. Данните са от създаването на КЗД досега (2005-2017 г.).

Фигура 1. Съотномение допуснати/отхвърлени жалби към КЗД

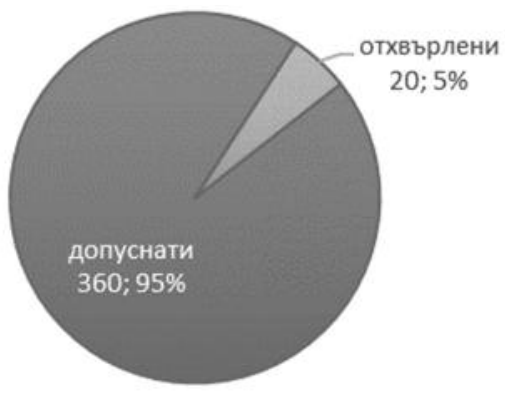

В голямата си част получените жалби се групират в няколко основни групи:

1. Нарушен или отказан достъп до медицинска услуга;

2. Засегнати права̀ на пациента, респ. човешки права̀.

Акцентите в оплакванията за твърдени нередности са следните:

- дискриминация в рамките на трудови и служебни правоотношения в системата на здравеопазването;

- експертиза на работоспособността, включително дейността на Националната експертна лекарска комисия (НЕЛК);

- липса на финансиране и недостатьчно финансиране на здравни дейности, включително ограничения в бюджета на лечебни заведения, недофинансиране на клинични пътеки и други;

липса на условия, които да позволят прилагането на съвременни терапевтични способи, включително липса на терапевтична уредба;
> неосигуряване на медицински изделия и диетични храни за лица, страдащи от определени заболявания;

- по-неблагоприятно третиране вследствие на отказ от ваксинации;

- липса на нормативна уредба, регламентираща възможността за приложение на така нареченото „състрадателно лечение“; заведения;

р регламентиране на хранителни режими в детски

> неосигуряване на възможност за контакт между родител и новородено от страна на медицински лица;

- тормоз на пациента от страна на медицински лица;

- определяне на възрастови ограничения във връзка с ползването на медицински услуги;

- неравно третиране относно осигуряването на лечение на деца в чужбина;

- здравно обслужване в училищното образование;

- неравно третиране на лица - граждани на трети страни, които са членове на семейството на български граждани във връзка с предоставянето на медицински услуги;

- законова нормативна уредба, регламентираща здравното осигуряване на определени групи физически лица да се извършва със средства от държавния бюджет;

- условия за придобиване на специалност в системата на здравеопазването;

- признаване на професионални квалификации, придобити в чужбина;

- условия за достъп до медицинска помощ в затворнически общежития;

- невключване в реимбурсния списък на определено скъпо лекарство за хората с редки болести и липсата на субсидирането му от държавата;

- осигуряване на лечение само на тези от тях, които са с до 65 на сто инвалидност;

- отказ на институциите да финансират изцяло или отчасти закупуването на апарати за деца с кохлеарна глухота, или инсулинови помпи за деца, болни от диабет;

- оплаквания, засягащи лечението на онкоболните в държавата, в това число животоспасяващите лъчетерапия и химиотерапия и алтернативните методи като имуностимулиращата терапия, индикират за необходимост от цялостното привеждане на медицинските грижи в тази област до съвременно равнище;

- лишаване от достьп до определени методи на асистирана репродукция, като се приема, че формалният възрастов критерий е неоправдан, а трябва индивидуална преценка на репродуктивното здраве на всяка отделна жена.

\section{Жалби и сигнали до ИАМО}

ИАМО е орган, специално създаден и натоварен с отговорността да извършва контрол в здравната система. Той извършва специализирана контролна дейност и има специално регламентирани правомощия от законодателя в тази област. Периодът на проучването е 2012-2017 г. - 3472 жалби. Постъпили са и повторни жалби и писма, в които е изразена неудовлетвореност от констатациите от първичните проверки. Фигура 2. Жалби и сигнали към ИАМО за 2012-2017 г.

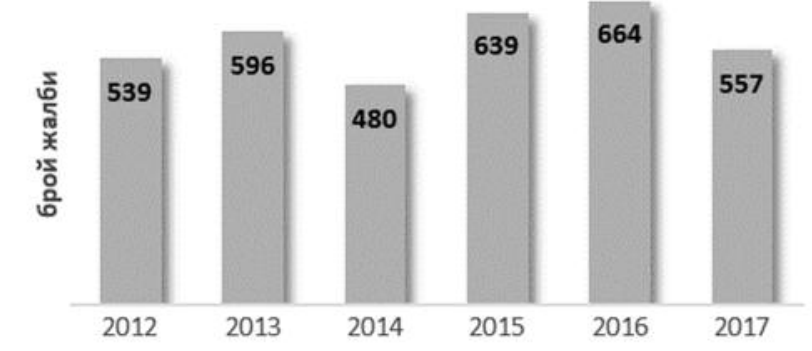


Най-много жалби има в периода от 01.01.2015 г. до 30.06.2016 г., когато са постъпили общо 1027 жалби, 19.4\% от които или 199 жалби се отнасят за случаи с настъпил неблагоприятен (летален) изход. Тринайсет от постьпилите жалби се отнасят за случаи с настъпил летален изход при новородени и деца. От постьпилите жалби, при които е настыпил неблагоприятен (летален) изход са извършени проверки по 155 жалби, 13 са насочени по компетентност към други институции. Не е извършена проверка по 14 жалби поради това, че липсва законово основание за извършване на проверка.

Фигура 3. Видове жалби и сигнали към ИАМО

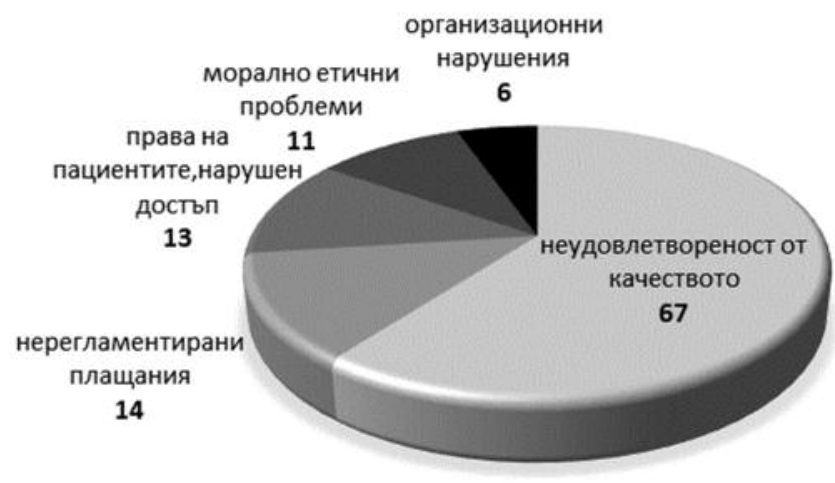

Най-често поставяните проблеми в жалбите и сигналите, постьпили в ИАМО, са следните:

- неудовлетвореност от качеството на оказаната медицинска помощ;

> нарушени права̀ на пациентите/затруднен достъп до медицинска помощ;

> организационни нарушения;

- нерегламентирани плащания;

морално-етични проблеми;

други.

Сигналите за неудовлетвореност от качеството на оказаната медицинска помощ през целия анализиран период (2012-2017 г.) съставляват 60-70\% от всички. Проблемът с оценка на качеството на медицинската помощ изисква целенасочени действия от компетентните органи.

Други институции също са насочвали жалби към ИАМО, като най-често това е МЗ с РЗИ като регионални структури на МЗ, органите на съдебната власт, НПО, Парламент и омбудсман.

Фигура 4. Дял на регистрирани жалби към ИАМО от други институциии

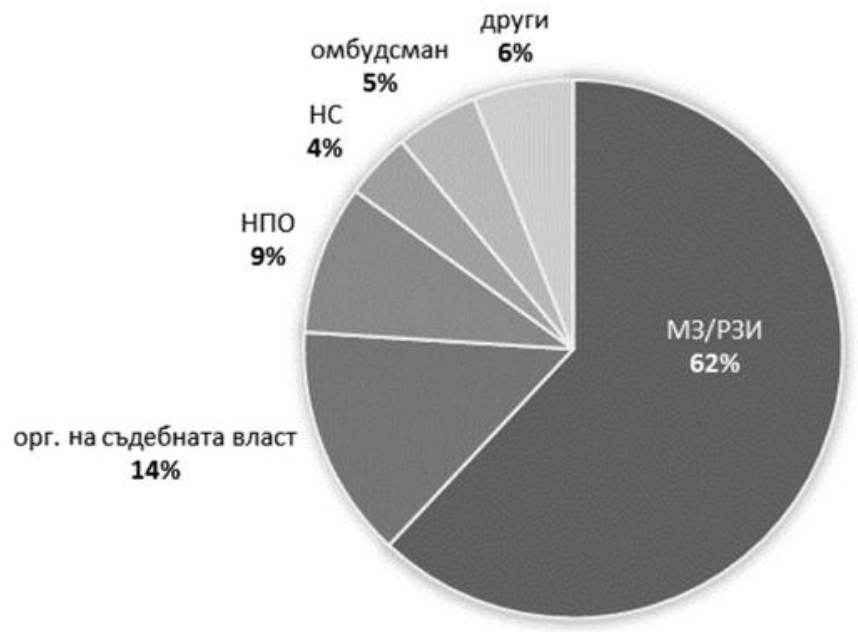

Сигналите, насочвани от структурите на съдебната власт се увеличават трайно.

Фигура 5. Сигнали от органи на съдебната власт, насочени към ИАМО за 2013-2015 г.

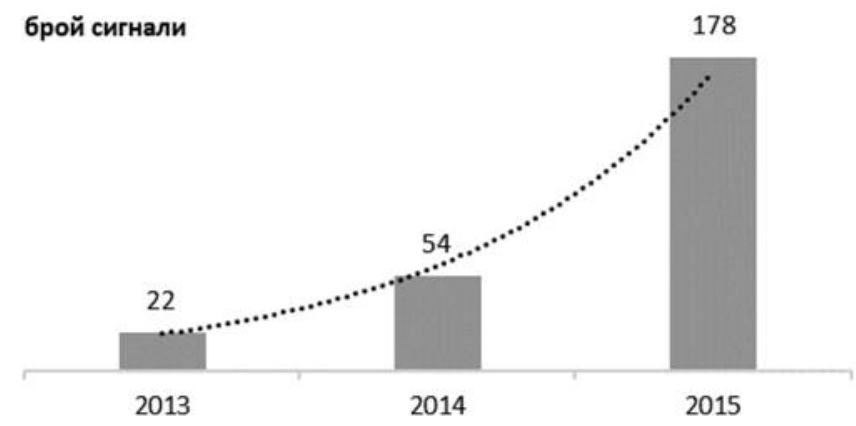

Сезиране на съдебната система

През периода 2010-2017 г. са заведени 238 съдебни дела. През 2007-2010 г. са заведени под 25 дела. За периода 2011-2017 г. броят на заведените дела е около 40 броя годишно. За целта са извършени множество съдебно-медицински експертизи. Само 17 от тези дела са решени без съдебно-медицинска експертиза. При над $30 \%$ от делата са назначени повече от една експертиза. Най-вероятно това е една от причините за бавното разрешаване на съдебните дела (от 1 до 10 г. ). 45 от заведените дела са висящи.

Фигура 6. Брой заведени дела по години

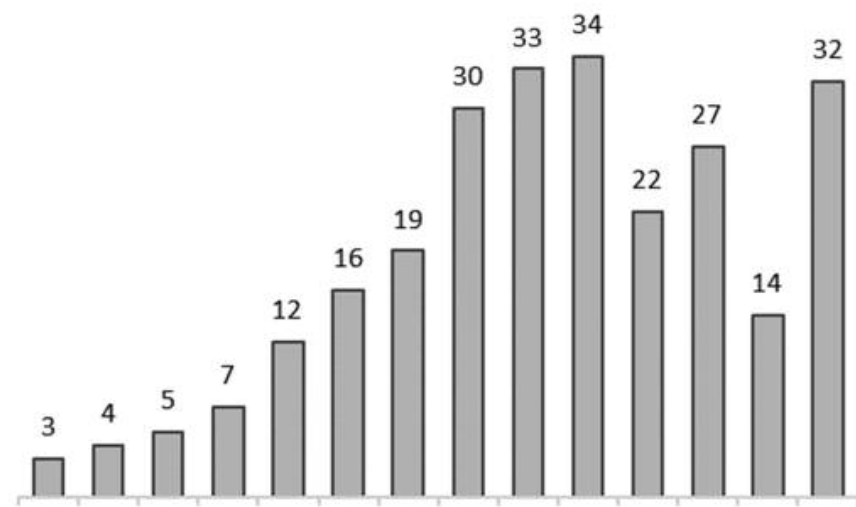

20042005200620072008200920102011201220132014201520162017

Противоправните деяния включват не само допуснати грешки в лечебно-диагностичния процес, но и други по вид действия и бездействия. Не всички предявени искове са уважени - една част са квалифицирани като неоснователни.

Фигура 7. Основателност на заявените искове

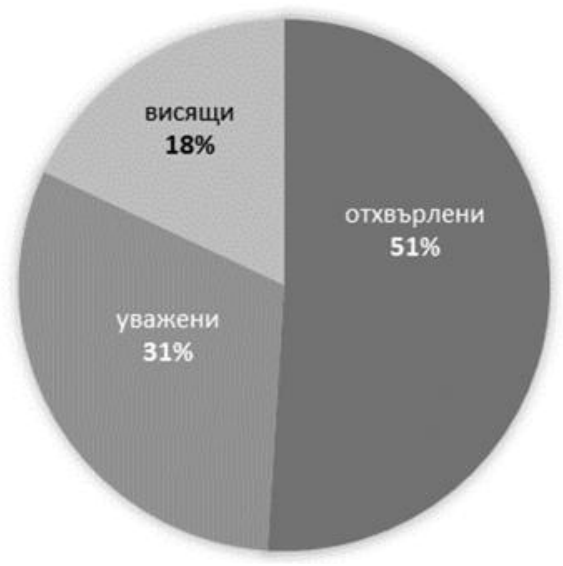


В България не е популярна практиката за извънсъдебно уреждане на спорове.

\section{Обсъжаане}

Броят на жалбите, отправяни към дадена институция, най-вероятно се влияе от доверието към нея, но и от проблемите в сектора, за който се отнасят. Ето защо се предполага, че те представят сравнително достоверно дефицитите и потребностите от корекции от гледна точка на пациентите, а смисъльт е да се реши не просто личният проблем, засягащ жалбата, а да се превантират следващи подобни проблеми и взаимоотношения. Броят на жалбите и сигналите на граждани за проблеми в здравната система (2772 броя), отправени към Омбудсмана имат трайна тенденция на нарастване [2]. Структурата на проблемите показва устойчивост през целия дванадесетгодишен период от съществуването на институцията на Омбудсмана по отношение на теми като достьп и качество на медицинската помощ (МП) и проблемите на трудовата експертиза. Същото се установява и при ИАМО, както и при КЗД $[1,3]$.

Съдебните решения, засягащи взаимоотношенията в българската здравна система са малко на брой, най-вероятно поради много фактори, включително финансови, забавяне във времето, съмнение в експертизата и обективността и т. H. [6].

\section{Изводи}

Пациентите имат нагласа за защита на собствените и на своите близки интереси в областта на медицинското обслужване и медицинското право. Нараства броят на подаваните сигнали и това е трайна тенденция. Дори и след извършена проверка от компетентните институции и органи, те се интересуват от резултатите, от констатациите, от наложените санкции и нерядко - макар и понякога чисто субективно, се обръщат за повторна проверка.
Сигналите за неудовлетвореност от качеството на оказаната медицинска помощ през целия анализиран период съставляват 60-70\% от всички жалби към обследваните компетентни органи, получаващи жалби и сигнали. Проблемът с оценка на качеството на медицинската помощ изисква целенасочени действия от компетентните органи (Министерство, съсловни организации, научни дружества).

Може да се приеме, че анализът на подаваните жалби достоверно отразява проблемите в здравната система през погледа на пациентите, като броят на жалбите и сигналите, тяхната допустимост, но и дельт на неоснователните такива са различни при различните институции и зависят от тяхната способност за експертиза, компетентности и правомощия.

Съдебните решения, засягащи взаимоотношенията в българската здравна система, са малко на брой, най-вероятно поради много фактори, включително финансови, забавяне във времето, съмнение в експертизата и обективността, но също имат тенденция да растат.

\section{Библиография}

1. Годишни отчети за дейността на КЗД 2005 - 2017г., www.kzd- nondiscrimination.com

2. Годишни отчети за дейността на Омбудсмана на Р. България 2005 2017 г, www.ombudsman.bg/dokuments/gd

3. Годишни отчети за дейността на ИАМО 2012-2017г., eama.bg

4. Отговор на запитване до КЗД относно сигнали и жалби, отправени към КЗД във връзка с проблеми в здравната система за периода 2005 -2017г., 60-00-99от 10. 09. 2018 г.

5. Илиева А., Контрольт в здравеопазването, Сиела, 2018, ISBN 978954-28-2541-8

6. Шаркова М., Медицинският деликт, под редакцията на Д. Доковска, 2018

7. Gostin L. O.,The Right to Health:A Right to the Hghest Attainable Standarts of Health.HASTINGS CENTER REPORT 29-109(2001)

8. Swendiman K. S. Health Care: Constitutional Rights and Legislative Powers, Juli 9,2012

\section{нови КнИгИ}

\section{Хеморагичната треска с бъбречен синдром и Кримско-Конго хеморагична треска М. Пишмишева, И. Христова, Н. Ватев, изд. Изток/Запад, 2018, 138 с.}

Интересът към вирусните хеморагични трески не стихва поради разширяване на ареалите на разпространение, нарастване на заболяемостта, трудната диагноза и неприемливо високия леталитет. Тези заболявания са природно-огнищни, транмисивни зооантропонози, с ограничени ареали на разпространение. Нашата страна е ендемична за Хемогагичната треска с бъбречен синдром и Кримска-Конго хеморагична треска. Проучвания върху тези заболявания започват в средата на миналия век и българската наука има традиции и принос в проучванията на двете заболявания. Настоящата монография е логично и достойно продължение на научните търсения, и обобщение на постигнатото в познанията за вирусните хеморагични трески. Авторите предлагат съвременни данни за епидемиологията на тези тежки инфекции, нови данни за разпространението им у нас, в съседните страни, в Европа и света. Изключително важни са данните за възможностите на съвременната диагностика, която у нас тя се извършва от Националната референтна лаборатория по предавани с кърлежи патогени към НЦЗПБ, осигуряваща ранна диагноза на вирусните хеморагични трески. Монографията включва и практически препоръки за коректно набиране и транспорт на биологичните материали, детайлна клинична характеристика на тези заболявания и възможните терапевтични алгоритми. Обобщени са специфичните и неспецифични профилактични мероприятия - ефективни ваксини за имунопрофилактика, контрол върху популацията на гризачите и дезакаризационните мероприятия в природните огнища, обезкърлежаване на домашните животни и спазване на строг противоепидемичен режим при обслужване на болни. Монографията представлява едно съвременно ръководство за диагностика, терапия и превенция на Хемогагичната треска с бъбречен синдром и Кримска-Конго хеморагична треска. Книгата е адресирана към студенти и общопрактикуващи лекари, към инфекционисти, епидемиолози, вирусолози и други специалисти. Предоставената от авторите информация е значима, тъй като епидемиологичните данни са едни от опорните пунктове за ранната, коректна диагноза и свързаната с нея терапия и превенция на разпространението.

Из реценцията към монографията проф. д-р Мария Стойчева, ръководител катедра по инфекциозни болести, паразитология и тропическа медицина, МУ - Пловдив 